\title{
Por políticas públicas habitacionais sustentáveis no Rio de Janeiro: materiais não convencionais em interatividade com as particularidades socioambientais do território carioca
}

\author{
Public policies for sustainable housing in Rio de Janeiro: \\ Unconventional materials interacting with specific environments \\ in the territory of Rio de Janeiro
}

\author{
Lucas Alves Ripper \\ Augusto Cesar Pinheiro da Silva \\ Pontifícia Universidade Católica do Rio de Janeiro
}

\begin{abstract}
Resumo: As políticas públicas habitacionais na cidade do Rio de Janeiro destacam-se pelos fortes impactos ambientais causados por materiais construtivos produzidos pela indústria pesada. Estes materiais normatizaram a implementação da "moderna cidade carioca", desde o inicio do século XX. Neste trabalho busca-se analisar a potencialidade de utilização de bambu como material construtivo local alternativo para a produção de moradias populares destinadas às comunidades de baixa renda em programas habitacionais sustentáveis na cidade. Essa matéria-prima é utilizada na construção de casas populares há 25 anos em programas habitacionais latino-americanos que têm, como diretrizes, um baixo impacto ambiental e baixos custos para o produto final: a casa. O bambu tem um grande potencial de propagação e cultivo no território carioca bem como no Brasil, o que o torna um material fundamental para repensar políticas nos domínios da Mata Atlântica.
\end{abstract}

Palavras-chave: Manejo dos recursos. Técnica. Materiais não convencionais. Arquitetura vernacular. Sustentabilidade.

\begin{abstract}
The housing policies in Rio de Janeiro are marked by a serious environmental impact caused by building materials that are produced with heavy industries. These materials have normalized the formation of "modern Rio de Janeiro" since the beginning of the twentieth century. Our investigation looks into the potentialities of bamboo as a construction material for the production of local homes among popular low-income communities in sustainable housing programs in the city of Rio de Janeiro. Since 25 years, it has been used as raw material for the construction of popular houses in Latin American housing programs which have, as guidelines, low environmental impact and cheap costs for the final product, the home. Bamboo has a great potential as it can be easily propagated and cultivated specifically in the region of Rio de Janeiro, but also all over Brazil. This makes it an important material for rethinking the policies in areas of the Atlantic Rain Forest.
\end{abstract}

Keywords: Resource management. Techniques. Unconventional material. Vernacular architecture. Sustainability. 


\section{APRESENTAÇÃO}

Em suas diversas formas de ocupar o espaço, o homem trabalha na confecção de objetos para apoiá-lo nesta construção. À medida que a história vai sendo socialmente construída "a configuração territorial é dada pelas obras dos homens: estradas, plantações, casas, depósitos, portos, fabricas, cidades etc.; [...]" (SANTOS, 2002, p. 62), e essa configuração, na visão do autor, é cada vez mais o resultado de uma produção histórica e tende à negação de uma natureza natural, substituindo-a por uma natureza inteiramente humanizada.

A base material para a construção objetal humana é provinda de tal natureza natural, a também chamada primeira natureza (ORTEGA Y GASSET, 1963), transformada pela ação humana em recurso para o estabelecimento de espaços de convivência. Seja no meio rural ou urbano, a matéria-prima disponível no ambiente é coletada e transformada em segunda natureza (Ibidem), que é humanizada pelo beneficiamento da matéria prima em estado bruto. Pensar a produção material do homem é pensar a produção do espaço de vivência: o homem fabrica seu espaço mediante seu empenho em transformar a natureza, ou seja, humanizá-la.

De acordo com Flusser (2007), a história do homem na terra é a história da fábrica, onde tudo que é dado (pela natureza) é convertido em algo feito, realizado (pelo homem). Para o autor, as fábricas são lugares em que os homens se tornam cada vez menos naturais e cada vez mais artificiais, $\mathrm{e}$ isto se dá precisamente pelo fato de que as coisas convertidas, transformadas, ou seja, fabricadas, reagem à investida do homem. Ainda nas palavras do autor:

[...] um sapateiro não faz unicamente sapatos de couro, mas também, por meio de sua atividade, faz de si mesmo um sapateiro. Dito de outra maneira: as fábricas são luga- res onde sempre são produzidas novas formas de homens: primeiro, o homem-mão, depois, o homem-ferramenta, em seguida, o homem-máquina, e, finalmente, o homemaparelho eletrônico. Repetindo: essa é a história da humanidade. (2007, p.37).

A análise da produção do espaço geográfico vista na definição de Santos (2001) como um conjunto indissociável de sistemas de objetos e sistemas de ações, perpassa também pelos objetos constituintes deste espaço. Tais objetos, se olhados do ponto de vista material de sua fabricação, uso e descarte, podem traduzir o tipo de relação que esta sociedade, produtora do espaço, cultiva com a natureza e como utiliza os recursos naturais disponíveis naquele ambiente. Como poderia então um objeto ser reflexo de uma ideologia de preservação da natureza? Como a arquitetura do objeto poderia manifestar em suas formas e conteúdos um ideal de preocupação com o meio ambiente em que se insere?

É comum para os habitantes do Rio de Janeiro a relação próxima entre a cidade e a natureza, a urbanização da cidade passou por grandes transformações em sua legislação de maneira a flexibilizar/adaptar a participação da natureza na morfologia urbana, o que impele a pesquisa sobre o espaço da cidade a se debruçar sobre "novas" formas de habitabilidade em conformação com as condições ambientais do espaço natural carioca, suas possibilidades e as idiossincrasias sociais.

\section{REFLEXÕES INICIAIS: A CASA SOB NOVOS OLHARES}

O debate ambiental em uma cidade "que vive a natureza como protagonista da vida urbana" (MAGALHÂES, 2002, p. 23) é algo bastante difundido, ocorrendo pesquisas de cunho ambiental nas diversas áreas da academia, como na Engenharia, na Geografia, no Design, Arquitetura, Geotecnia e outras. 


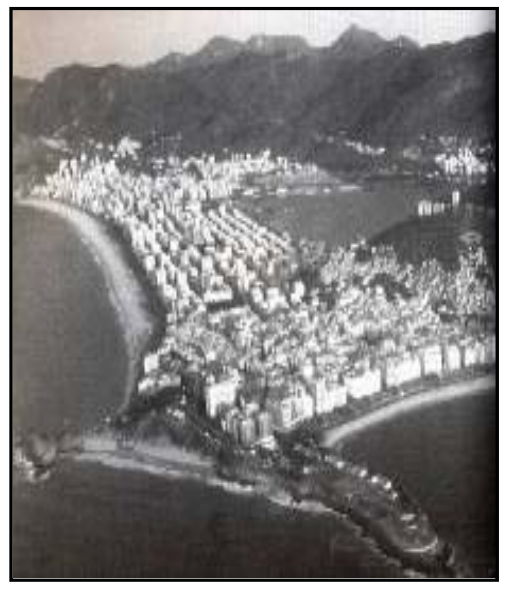

Fonte: Magalhães, 2002, p. 20.

Figura 1: Parte da Zona sul carioca, bairros da cidade readequados à morfologia do seu sítio urbano.

Frente ao debate atual sobre as sustentabilidades da vida urbana devido à escassez de recursos essenciais da biosfera (água potável, qualidade do ar atmosférico, temperaturas aprazíveis, deposição de lixo e resíduos sólidos...), a habitalidade urbana, seja na cidade formal ou informal, vem ganhando as agendas da pesquisa e tecnologia nos projetos de gestão dos territórios, e a cidade do Rio de Janeiro não é uma exceção.

Tanto na zona Sul carioca como nas favelas, o problema ambiental referente ao lixo e resíduos sólidos é o mesmo. Restos da construção civil e esgoto in natura são descartados "pelo ralo", e desconsiderados ou desconectados dos sistemas infraestruturais do espaço de vida do carioca. Por exemplo, no Complexo da Maré (composto por ex-favelas), na zona Norte, a poluição por resíduos sólidos provenientes da construção civil é tão grave quanto à gerada pelas construções irregulares de casas de alta classe média às margens de áreas de manguezal e lagunas na zona Oeste, o que torna este um dos principais problemas ambientais da "Cidade Maravilhosa".

A produção - e reprodução - da cidade é um tema complexo; pontes, ruas, postes de luz, emissários submarinos, e toda materialidade que envolve esta produção, é prevista e projetada pelos profissionais das diversas áreas em prol da criação de um espaço - sistemas de objetos e sistemas de ações - que possibilitem a vida do homem em sociedade. Se esta produção não for olhada de uma maneira complexa - pensando a fabricação associada ao uso, a manutenção e o descarte - ela pode acarretar problemas ambientais como os observáveis, por exemplo, na Baía de Guanabara, no Rio de Janeiro. O local sofre com o desgaste material das moradias na baía, algo não previsto no momento de construção das habitações.

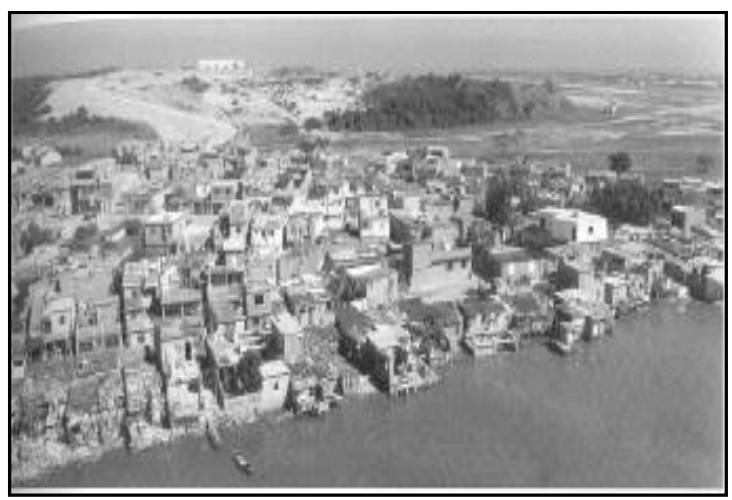

Fonte: Magalhães, 2002, p. 45

Figura 2: Complexo da Maré. Detalhe para o desgaste material dos barracos na marginal, resíduos sólidos da construção civil que escoam para dentro da Baía de Guanabara.

A confluência entre os saberes acadêmico e tradicional, ou etnociência (DIEGUES, 1994), na construção de habitações é focal neste trabalho, que se propõe repensar a produção (e reprodução) do espaço urbano através da casa seja nas cidades ou no campo.

Tal confluência de tendências e ações em torno das decisões sobre a construção das casas e da estrutura de habitabilidade no espaço geográfico serão observadas partindo-se do recorte espacial "cidade do Rio de Janeiro". Desde o século XVII, a sua evolução urbana é marcada pelo uso dos materiais construtivos tradicionais nas 
edificações da cidade, causando impactos diretos no meio ambiente carioca. Porém, a tradição da construção civil com o uso da alvenaria se formalizou no século $X X$, notadamente a partir da década de 1930, quando foi consolidado o padrão norteamericano de progresso e modernização pautados na produção industrial e exploração de materiais construtivos prédeterminados e exportados para variados lugares.

No período pós- $2^{\mathrm{a}}$ Guerra Mundial, o pensamento moderno influencia em muito a construção da urbanidade carioca, sendo esta baseada na produção industrial massiva. "A crença no progresso linear, nas verdades absolutas e no planejamento racional de ordens sociais ideais sob condições padronizadas de conhecimento e de produção" (HARVEY, 1989, p.42) chega ao Rio de Janeiro sob o signo de Le Corbusier (MAGALHÃES, 2002).

Pela ordem, promover a liberdade foi um dos slogans de Le Corbusier, que enfatizou que a liberdade e a libertação da metrópole contemporânea dependem de maneira vital da imposição da ordem racional. O modernismo assumiu no período Entreguerras uma forte tendência positivista e, [...] o positivismo lógico era tão compatível com as práticas da arquitetura modernista quanto com o avanço de todas as formas de ciência como avatares do controle técnico. Foi esse período em que as casas e as cidades puderam ser livremente concebidas como "máquinas nas quais viver". (HARVEY, 1989, p.37).

Percebe-se o apoio "das máquinas", numa alusão à industrialização, à concretização do movimento em cenário urbano. O modernismo intelectual e estético promoveu a difusão de suas práticas materiais $[\ldots]$

[...] através das máquinas, dos novos sistemas de transporte e comunicação, os arranha-céus, as pontes e as maravilhas de todo tipo de engenharia bem como a instabilidade e insegurança incríveis que acompanharam a rápida inovação e mudança social (HARVEY, 1989, p.35).

Portanto, no período compreendido entre as décadas de 1920 e 1950, a forte corrente modernista chega à metrópole carioca e, do ponto de vista arquitetônico, instala as "indústrias de construção" (HARVEY, 1989, p.42) convencionando materiais construtivos com a finalidade de promover uma urbanização modernista.

Tomando-se como ponto de partida a evolução urbana do Rio de Janeiro a partir de $1608^{1}$, chega-se à pesquisa acadêmica e sua colaboração na inserção de materiais não convencionais à tradição da construção civil moderna como projeto político e ambiental.

À medida que a cidade era urbanizada, a paisagem natural foi sendo substituída por outra "inteiramente humanizada", contendo aterros nas lagoas pré-existentes, escavações e a quase total dizimação de florestas e ecossistemas lagunares. Este foi um período em que havia somente habitações dispersas no espaço carioca e populações de índios das florestas integrados ao "meio natural". Com este suporte, pode-se compreender com mais clareza os caminhos que levaram "aquele" Rio de Janeiro a se tornar a atual "Cidade Maravilhosa" que conhecemos.

Tal percepção histórica tem, por objetivo, estimular, na atualidade, a inserção de materiais não-convencionais na construção da habitação na cidade carioca. Tal inserção necessitará, contudo, da implementação de políticas públicas sustentáveis que valorizem a potencialidade do uso de materiais diversos como, por exemplo, o bambu e a terra crua, na constituição de

${ }^{1}$ A opção pelo recorte espaço-temporal '1608 no Rio de Janeiro' tem o intuito de identificar as características geofísicas do território carioca sem interferência humana, já que, segundo Andreatta (2006, p.20), foi a partir do "início do século XVII que as transformações ambientais mais expressivas passaram a ser observadas na cidade de São Sebastião do Rio de Janeiro". 
habitações urbanas em diversos pontos da cidade. Tais materiais já demonstraram diacronicamente a sua eficácia construtiva associada a técnicas de manejo sustentáveis à produção e reprodução do espaço do homem, em muitos lugares do mundo, como se verá mais adiante.

No Brasil e na Colômbia, bem como em outros países da América Latina, a utilização do bambu e da terra crua na constituição de habitações urbanas se mostra uma prática sustentável para a regeneração do meio, como pode ser comprovado nos recentes trabalhos realizados por pesquisadores latino-americanos. Dentre eles, destacam-se Oscar HIDALGO-LÓPEZ (2003), Jorge ARCILO (2003) e Fernando BETIM (2008), em estudos sobre a construção de casas populares, sustentáveis, resistentes e adaptadas à "forma-função" metropolitana dominante na América Latina. A regeneração da "gramínea gigante" - como é, vulgarmente, conhecido o bambu (Família Gramínea) - é a mais rápida do planeta (MCLURE, 1993); porém, o seu manejo adequado deve privilegiar os conhecimentos e técnicas tradicionais (o corte dos colmos maduros na lua minguante). Em relação à terra crua, um manejo correto deve privilegiar a localização de coleta no terreno, o popularmente conhecido "barreiro", que deve ser acessado em determinado local onde se colete a quantidade necessária que não cause danos à estrutura do solo, gerando erosão e atividades de voçorocamento, que prejudicam tanto o ecossistema local quanto à manutenção da moradia naquele espaço.

Habitações vernaculares ${ }^{2}$ construídas

\footnotetext{
${ }^{2}$ Chama-se vernacular algo "próprio da região em que existe, sem estrangeirismo, castiço" (AURELIO, 1988, p.524). De acordo com alguns arquitetos, o termo Arquitetura Vernacular corresponde às formas desenvolvidas em um longo período de tempo por populações que habitam um determinado ambiente. Esse tipo de arquitetura se caracteriza por se utilizar da matéria prima disponível no local, e com ela construir as moradias necessárias para a subsistência do povo. O processo de obtenção destes recursos naturais locais era realizado de maneira a não comprometer a repetição desta prática de produção por parte das gerações futuras.
}

não somente com o uso do bambu e da terra, mas por fibras vegetais em geral e madeira, são abundantes em território sulamericano, e poderiam ser incentivadas, no Brasil, por políticas públicas especificas como já ocorre a algum tempo em países como a Colômbia, o Equador e o México. Essa percepção (a da presença abundante de materiais resistentes e pertencentes às paisagens sul-americanas) não é recente. Em passagem pela América do Sul, em 1801, Alexander Von HUMBOLDT analisou os "selvagens bambus" utilizados pelos nativos da Região de Quindio, no Vale de Cauca (Colômbia). Conhecido como Guadua, o bambu é destacado pela sua impressionante morfologia que ajuda nas utilizações na arquitetura local.

Alexander von Humboldt [...] escreveu na sua narrativa de viagem que "de todas as formas de vegetação entre os trópicos, o bambu e mais três tipos de fetos arbóreos (samambaias) constituem a mais poderosa impressão a partir da imaginação do viajante" (HUMBOLDT, 1900). O pesquisador descreveu a presença abundante do bambu durante o seu período em Quindio, em uma zona de colinas onduladas cobertas pelas recentes cinzas da atividade de vulcões, quase inabitada, onde os aborígenes há muito tempo foram dizimados pela guerra e por doenças européias. (FRIEDE, 1963 apud THE GEOGRAPHICAL REVIEW, 1991, p.2).

\section{BASE TEÓRICO-METODOLÓGICA DA PESQUISA}

Como um dos principais instrumentos para a subsistência do homem no meio urbano, a habitação na metrópole carioca será identificada na sua relação com a natureza que compõe a força do espaço urbano do Rio de Janeiro. Levanta-se a questão da materialidade da habitação moderna, 
envolvendo seus materiais constituintes e formas arquitetônicas, além da sua fabricação. Como metodologia de estruturação do pensamento acerca da construção da casa, deve-se valorizar o desenvolvimento de estratégias "menos impactantes" para a ocupação do espaço, sob um ponto de vista ambiental de complexidade, investigandose o ciclo de vida desse objeto (a casa) à luz do debate de Edgar Morin sobre o pensamento complexo (2005).

O ciclo de vida do objeto construído envolve sua criação, manutenção e posterior descarte. Uma análise critica desse ciclo permite identificar, de uma maneira complexa, a produção material (fábrica), considerando as fases de concepção, "gestação", produção, uso, manutenção e descarte. Observando-se de uma maneira simplista considera-se a produção de um objeto a partir de uma determinada demanda, justificando assim a sua concepção material, forma e conteúdo para o cumprimento (de forma eficaz ou não) de determinada função e uso. Entretanto, quando salientada a relação de produção - ou fabricação - a partir da sua matriz material, destaca-se o caráter do uso dos recursos naturais disponíveis, que pode ou não possuir um caráter meramente utilitarista da natureza, sendo que populações tradicionais espalhadas pelo globo demonstram diacronicamente formas variadas de relação com a natureza, através da utilização dos variados recursos.

Valorizam-se, neste trabalho, formas sociais de mediação da natureza que beneficiam a adaptabilidade do homem no espaço, por meio da produção material e, simultaneamente, a regeneração dos recursos naturais utilizados (MARQUARDT, 2006). Frisa-se ser esta uma relação necessária para a subsistência do homem no espaço por intermédio da técnica ou pelo conjunto delas, que transformam matérias primas em materiais construtivos necessários a sua subsistência. A produção (e reprodução) do espaço do homem, portanto, envolve um complexo sistema de ações: a) de manejo dos recursos naturais disponíveis, b) de transformação destas matérias-primas em materiais outros, e, finalmente, c) de construção de objetos que irão apoiar a vivência (ou sobrevivência) do homem no espaço.

$\mathrm{Na}$ figura posterior pode-se identificar uma habitação construída com técnicas tradicionais Guarani. O caráter de baixo impacto desta habitação se apresenta na etapa de coleta da matéria-prima in situ e na etapa de descarte do material construtivo. A retirada da palha de Guaricanga (almeira comum na região Sul fluminense, em ambiente de Mata Atlântica) é feita nas épocas de lua minguante, quando são identificados os indivíduos com a maturidade certa para serem coletados de maneira que não seja danificado o ciclo de regeneração da planta. Dessa forma, a coleta da matéria prima não provoca a morte da palmeira se respeitados os seus padrões naturais. Já a terra crua é resultante do desgaste de outros materiais como as rochas, árvores e plantas em geral, e seu tempo de regeneração é bastante diferente do dos

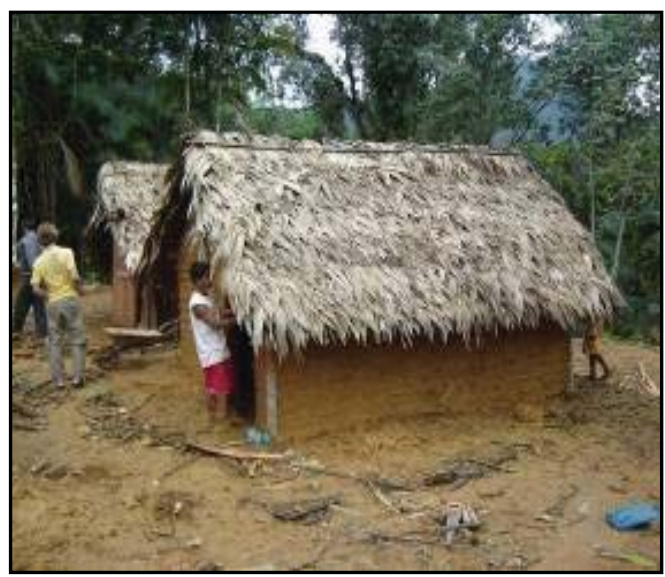

Fonte: Arquivo pessoal. Lucas Ripper, 2007.

Figura 3: Casa de pau-a-pique Guarani. Baixa impactação na coleta de matéria prima e no descarte da moradia. Aldeia Sapukai, Bracuí, Angra dos Reis, Rio de Janeiro, 2007. 
vegetais. A sua retirada no meio para a utilização na construção das casas requer cautela, pois uma má escolha do local de coleta e do ferramental e técnicas utilizadas podem gerar problemas de erosão de solo, ravinas e voçorocas, problemas que podem comprometer a habitabilidade do homem no meio.

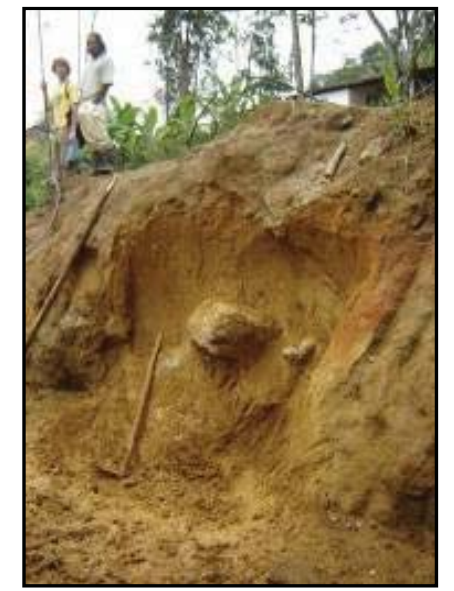

Fonte: Arquivo pessoal. Lucas Ripper, 2007.

Figura 4: O barreiro, local adequado do terreno para se retirar a terra crua sem causar danos ao ambiente. Aldeia Sapukai, Bracuí, Angra dos Reis, Rio de Janeiro, 2007.

Dessa forma, as práticas amparadas por técnicas adequadas de manejo dos recursos podem ser entendidas como suportes fundamentais das sustentabilidades na construção de objetos que propiciem a regeneração dos recursos nos seus meios. Neste sentido, como afirma ORTEGA Y GASSET (1963, p.X), “(...) a técnica é alguma coisa característica do homem, alguma coisa superior a experiência, mas inferior ao raciocínio, ao saber, que é justamente aquilo que a técnica faz possível ao propiciar ao homem o atendimento de seus desejos mais veementes".

Já Spengler (1931 apud ORTEGA Y GASSET, 1963) afirmava que a técnica é a tática de vida, ou seja,

uma teoria da técnica exige uma teoria da vida humana, sem a qual o fato da técnica resulta incompreensível. Isto porque no fundo, a técnica é um recurso [e que] "na vida do homem, ela (a técnica) é uma presença ubíqua, submergente, avassaladora, não se limitando à produção e ao emprego dos recursos para subsistência material da vida, (grifo nosso), mas atingindo a cada uma das ações humanas (1963, p. X).

Debates ambientalistas, desde meados da década de 1960, já alertavam a humanidade a respeito dos danos à fauna e à flora, em escala mundial, provenientes de uma racionalidade utilitarista dos recursos naturais, e que tal perspectiva necessitava de ressignificação frente aos avanços tecnológicos da sociedade, a partir de premissas de desenvolvimento e sustentabilidades. Outra leitura deste mundo em degradação coloca a técnica como o emprego predatório da natureza. A técnica, o recurso do homem em prol da produção do espaço, sendo utilizada de maneira a considerar a natureza como um "banco material", não considera a própria movimentação da natureza no sentido da manutenção, da reprodução e do desenvolvimento dos ecossistemas - os biomas, animais e as plantas neles contidos - assim como dos seres humanos. Sem dúvida, a raiz dos problemas de escassez de matéria prima e da degradação ambiental dos dias atuais perpassa pela consideração da natureza apenas como recurso, a partir de uma racionalidade econômica meramente utilitarista de técnicas aperfeiçoadas e desenvolvidas. $\mathrm{O}$ manejo da $1^{\mathrm{a}}$ natureza ocorre em velocidade crescente e a sua macro-escala de existência culmina na sua comercialização global como $2^{\mathrm{a}}$ natureza ou natureza beneficiada (ORTEGA Y GASSET, 1963).

Em um pólo oposto, analisa-se um conjunto indissociado de sistemas de ações e sistemas de objetos que privilegiam a regeneração da natureza com seus recursos. Esta é uma característica de populações vernaculares que consolidaram os seus 
habitats, desenvolvendo os seus ambientes sem extinguí-los ou escasseando os recursos utilizados por longos períodos.

A utilização dos recursos respeitando-se o seu tempo de regeneração caracteriza, segundo Leff (2006), uma racionalidade ambiental que se choca com a racionalidade econômica dominante em nosso mundo contemporâneo, mundo no qual a produção (e reprodução) do espaço deixa de ser somente uma produção social (LEFÈBVRE, 1973) ou cultural, para ser também produção (e reprodução) do capital (HARVEY, 1989). Santos (2002, p.63) afirma que "O espaço é hoje um sistema de objetos cada vez mais artificiais, povoado por sistemas de ações igualmente imbuídos de artificialidade, e cada vez mais atendentes a fins estranhos ao lugar e aos seus habitantes".

Baudrillard (1968, p.213) completa esse raciocínio chamando atenção que: "somos nós que os vemos - os objetos - hoje nascerem, perfazerem-se e morrerem, enquanto em todas as civilizações anteriores eram os objetos, instrumentos ou monumentos que sobreviviam ás gerações humanas".

Cada ponto geográfico no planeta possui condições físicas específicas. Aspectos como relevo, tipos de solo e vegetação, pluviosidade, fauna... compõem a identidade da natureza do lugar. Nesse sentido, o ambiente direciona, e às vezes condiciona, $\mathrm{o}$ homem na criação de sua materialidade, de maneira que nos pólos as habitações eram construídas com blocos de gelo - a matéria prima disponível - que é um material que deixa as casas bastante vedadas com objetivo de proteger o seu habitante do clima frio; em uma zona tropical de floresta úmida, populações diversas dispõem de uma variedade de materiais, como madeira e bambu para a construção de casas que protejam os habitantes do forte calor. $\mathrm{Na}$ figura 5, observa-se a arquitetura tradicional das mesquitas iranianas feitas em terra crua e madeira, técnicas que possibilitam a adaptação humana às características geográficas do lugar ao utilizar o principal material construtivo disponível no meio, a terra.

Conforme as determinantes geográficas,

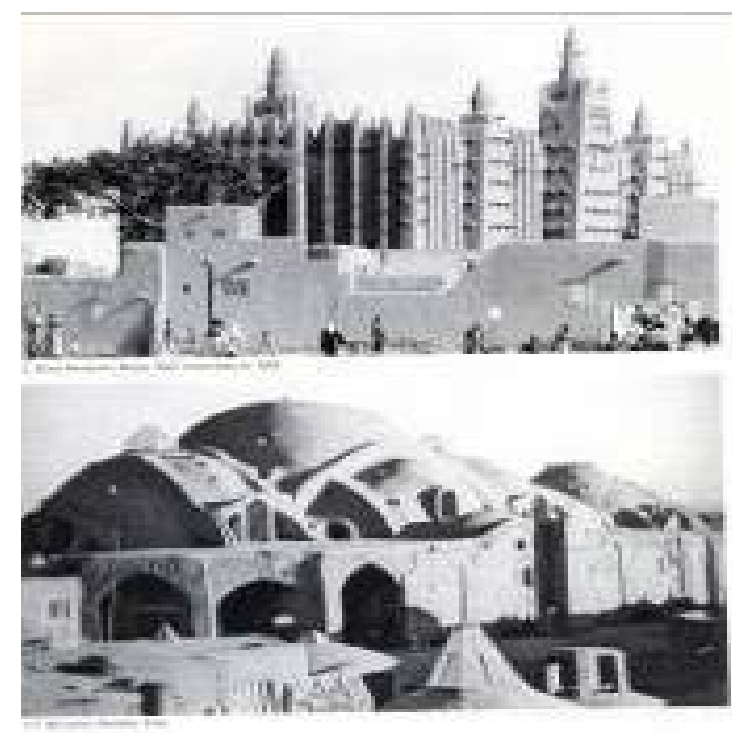

Fonte: Gernot Minke, 1994, p.14.

Figura 5: Arquitetura Vernacular em terra crua. Mesquitas, Mali, Irã. 1935.

arquiteturas específicas e eficazes podem ser definidas para o abrigo do homem. A construção das casas garante ao homem sua permanência no local e pode caracterizar o tipo de relação que ele preserva com seu entorno. Algumas populações "tradicionais" ${ }^{3}$, ao redor do globo apresentam arquiteturas eficazes e arrojadas associadas aos métodos adequados de manejo para preservação dos recursos naturais disponíveis. Na figura 6, a tradicional arquitetura vernacular colombiana em Guadua (bambu) comum da região, é adaptada ao relevo de alto declive característico da região montanhosa de Manisales (Colômbia) pelo arquiteto Jorge ARCILO ${ }^{4}$.

${ }^{3}$ A discussão sobre tradicionalismo, arcaísmo e modernidade não será o foco central deste texto, sendo mais ampla e reflexiva no corpo do trabalho de dissertação em curso.

${ }^{4}$ A arquitetura de ARCILO segue a tradição popular colombiana de construção em palafitas nas encostas íngremes montanhosas de Manisales com o Guadua Angustifólia, principal espécie de Bambu nativo do país. 


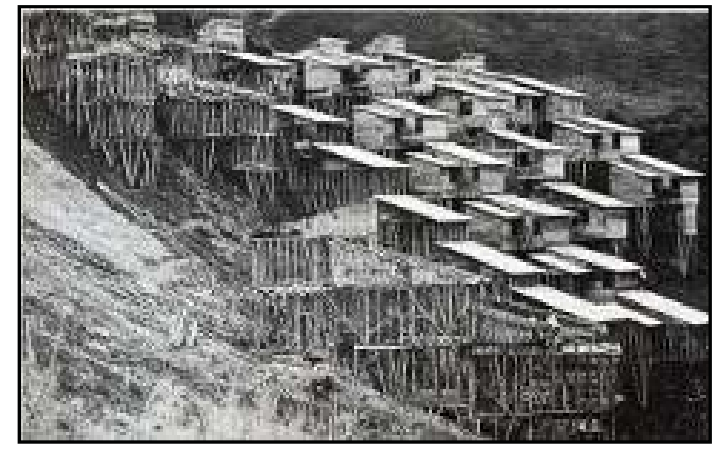

Fonte: Jorge ARCILO apud IL- 31, p. 292.

Figura 6: Habitações em Guadua (bambu) na encosta, arquitetura vernacular em palafitas, Manisales, Colômbia, 1983.

Os progressos técnicos e tecnológicos dos povos em relação à construção da casa têm se mostrado eficientes para a resolução de problemas arquitetônicos e para a viabilização de novas construções. Assim sendo, a casa do camponês, do caiçara ou do sertanejo, antes do domínio da modernidade (século XVI) no mundo apresentam técnicas singulares que, ainda hoje são taxadas como ultrapassadas ou não duráveis. Todavia frente aos problemas gerados na sociedade global pelas técnicas das Revoluções Industriais (a poluição atmosférica envolvendo a eliminação de gases-estufa, a devastação de florestas e a escassez de matérias primas), tais saberes passaram a ser ressignificados na ideologia desenvolvimentista ${ }^{5}$.

Desse ponto de vista, os saberes tradicionais que viabilizam a moradia do homem no espaço não se mostram tão rudimentares ou atrasados, pois são baseados em sistemas eficientes de uso dos recursos naturais associados à preservação e conservação, possibilitando a sua utilização com eqüidade em regeneração desses recursos em meios diversos. Diegues (1993) cita o exemplo da preservação da natureza promovida por populações tradicionais que moram no interior de

${ }^{5}$ As concepções de desenvolvimento também não serão aprofundadas neste texto, sendo observadas, no entanto, no corpo da dissertação em curso. áreas protegidas. Segundo o autor, esses indivíduos "se organizados e estimulados, poderiam contribuir positivamente para a conservação das áreas protegidas" (p. 221). Ainda seguindo o raciocínio de Diegues, percebe-se que as ações que viabilizam a moradia desses indivíduos no espaço (como, por exemplo, o cultivo, criação de animais, definição das redes de locomoção, construção das casas...) perpassam por uma produção material compatível com a regeneração dos ecossistemas.

Marquardt (2006) se refere à sustentabilidade a partir da idéia básica de que uma sociedade não deve usar uma quantidade de recursos maior do que a capacidade deles (os recursos) se regenerarem em seu meio, para que as próximas gerações possam ter as mesmas oportunidades de acesso. $\mathrm{O}$ limite de uso dos recursos para o desenvolvimento das atividades das sociedades depende da "capacidade e reprodutividade intergeneracional (grifo nosso) dos ecossistemas" (p. 174). Categorizando a sustentabilidade apontada pelo autor, pode-se afirmar que se trata de uma "sustentabilidade ambiental", ou da "sustentabilidade de uso dos recursos naturais" com objetivo de promover sua regeneração para que se garanta o acesso, novamente, no futuro.

Diegues (1993) completa esse raciocínio colocando em pólos opostos duas posições: a do homem que se coloca frente à natureza - mais 'ecocêntrica', em que o mundo natural tem um valor em si mesmo, independente da utilidade que venha a ter para o homem - e a segunda, mais antropocêntrica, que reafirma a primazia do homem sobre o mundo natural. De acordo com o autor, na primeira visão, o homem sempre se comporta como um dominador, um domesticador da natureza, sendo que esse comportamento leva, irremediavelmente, à destruição do mundo natural. Já na segunda visão, o mundo natural foi criado para 
benefício e uso do homem (Idem).

As ações de manejo dos recursos naturais disponíveis direcionadas para a construção da habitação por parte de populações tradicionais conferem um importante saber necessário para a busca de uma habitabilidade que envolva uma produção material menos nociva à natureza e que gere menos resíduos poluentes nas cidades.

$\mathrm{Na}$ figura a seguir (7), um exemplo concreto de uma nova habitabilidade nas Américas. As viviendas populares do arquiteto Oscar HIDALGO-LOPEZ têm como ponto fundamental a utilização da principal matéria prima nativa das florestas colombianas, a espécie de bambu Guadua Angustifólia, do gênero Guadua comum das Américas. Para o arquiteto, a utilização do bambu nativo na arquitetura colombiana é de grande importância para a criação de uma consciência ecológica, e gera um sentimento nacionalista nos estudantes de arquitetura envolvidos.
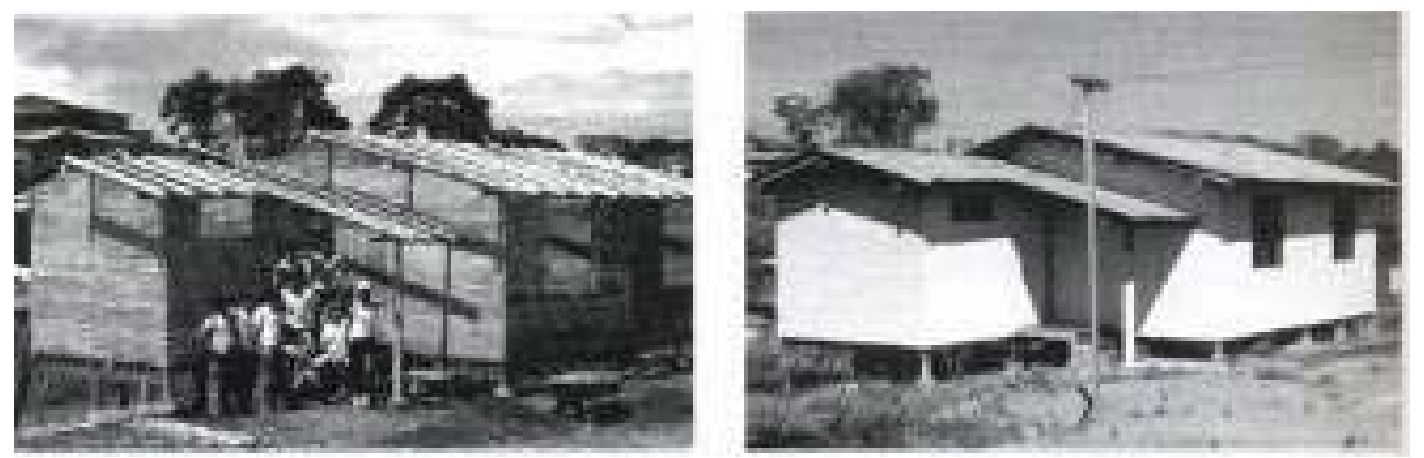

Fonte: Hildago-López, 2003, p. 280.

Figura 7: Viviendas Populares. Saber vernacular e acadêmico em confluência para soluções de moradias urbanas com baixa impactação ao meio ambiente. Colômbia, 1984.

Nesse sentido, esta pesquisa é interdisciplinar e envolve a Geografia, Arquitetura, Engenharia, Design e Agronomia, basicamente, podendo demonstrar a potencialidade da inserção de materiais não convencionais pouco modificados na construção civil em ambientes onde há uma enorme quantidade de materiais duráveis, resisten- tes e sustentáveis em consonância com os lugares; tal pesquisa, associada aos saberes tradicionais empiricamente construídos, pode garantir a produção dos objetos casas - respeitando-se a preservação de sua matriz material através de métodos de manejo adequados para a regeneração dos recursos naturais disponíveis em diversos meios. Salienta-se a potencialidade do Brasil, especificamente do Rio de Janeiro, no desenvolvimento de políticas públicas habitacionais que contemplem a inserção destes "novos materiais" na produção do espaço urbano, tendo em vista que eles se tornaram objetos de consumo na vida do homem moderno, que pode melhorar em muitos sentidos a finalidade da existência nas cidades e campos do país.

\begin{abstract}
ANDREATTA, Verena. Cidades Quadradas, Paraísos Circulares - Os planos Urbanísticos do Rio de Janeiro no século XIX. Rio de Janeiro: Mauad Editora Ltda, 2006.
\end{abstract}

ARCILO, Jorge. IL 31 Bambus - Bamboo. Institute for Lightweight Structures (IL), University of Stuttgart, Alemanha: Director Frei Otto, 1985. 
BAUDRILLARD, Jean. O sistema dos objetos. São Paulo: Ed. Perspectiva, 1968.

BETIM, Fernando. A Casa que Respira: O fibrosolo como proposta de incorporação dos conceitos de aeração das moradias tradicionais utilizadas pelo homem do campo, nos espaços habitados pelo homem da cidade. 2008. Tese (Doutorado em Design) - Programa de Pós Graduação em Design, PUC-RJ, Rio de Janeiro - RJ.

DIEGUES, Antonio Carlos Sant Anna. “Populações Tradicionais em Unidades de Conservação: o mito moderno da natureza intocada". In: VIEIRA, Paulo Freire \& MAIMON, Dália (orgs.). As Ciências Sociais e a Questão Ambiental, rumo à interdisciplinaridade. Rio de Janeiro e Belem: APED e UFPA, 1993.

O mito moderno da natureza intocada. São Paulo: NUPAUB, USP. 1994.

FERREIRA, Aurélio Buarque de Holanda. Minidicionário da Língua Portuguesa. Rio de Janeiro: Ed. Nova Fronteira S.A., 1988.

FLUSSER, Vilém. O Mundo Codificado. São Paulo, Ed. Cosac \& Naify, 2007.

FRIEDE, J. Quimbayas bajo la dominación española. Bogotá: Banco de la República, 1963.

HARVEY, David. A Condição Pós-moderna. São Paulo: Ed. Loyola, 1989.

HUMBOLDT, Alexander von. Personal narrative of travels to the equinoctial regions 1799-1804. vol. 1. London: George Bell and Sons, 1900.

LEFÈBVRE, Henri. A Produção do Espaço. Paris: Ed. Anthropos, 1973.

LEFF, Enrique. A Racionalidade Ambiental. Rio de Janeiro: Ed. Civilização Brasileira, 2006.

MAGALHÃES, Sérgio. Sobre a Cidade - Habitação e democracia no Rio de Janeiro. São Paulo: Pro Editores, 2002.

MARQUARDT, Bernd. "Historia de la sostenibilidad. Un concepto medioambiental en la historia de Europa central (1000-2006)". Historia Crítica. n.32, p.173-197, ago. de 2006.

MCLURE, Floyd Alonzo. The Bamboos. Boston: Harvard University, EUA, 1993.

MORIN, Edgar. Introdução ao pensamento complexo. Ed. Sulina, 2005.

ORTEGA Y GASSET, José. Meditação da técnica. Rio de Janeiro: Ed. Ibero-Americana Limitada,
POR POLÍTICAS PÚBLICAS HABITACIONAIS SUSTENTÁVEIS NO RIO DE JANEIRO: MATERIAIS...

1963.

PARSONS, J.J. "Giant American Bamboo in the Vernacular Architecture of Colombia and Equador". The Geographical Review, vol. 81, n. 2 , abr. 1991, p.133.

SANTOS, Milton. A Natureza do Espaço. São Paulo: Ed. USP, 2002.

SANTOS, Paulo. Formação das cidades no Brasil colonial. Rio de Janeiro: Ed. UFRJ, 2001.

\section{FIGURAS}

Figura 1: MAGALHÃES, Sérgio. Sobre a Cidade - Habitação e democracia no Rio de Janeiro. São Paulo: Pro Editores, 2002, p. 20.

Figura 2: MAGALHÃES, Sérgio. Sobre a Cidade - Habitação e democracia no Rio de Janeiro. São Paulo: Pro Editores, 2002, p. 45.

Figuras 3 e 4: Acervo pessoal de Lucas Ripper, 2007.

Figura 5: MINKE, Gernot. Manual de Construccion en Tierra. Ed. Nordan Comunidad, Montevideo, Uruguay, 1994, p. 14.

Figura 6: IL 31 Bambus - Bamboo. Institute for Lightweight Structures (IL), University of Stuttgart, Alemanha, Director Frei Otto, 1985, p. 292.

Figura 7: HIDALGO, Oscar Lopes. Bamboo - The Gift of the Gods. Ed. D'VINNI Press LTDA, Bogotá, Colômbia, 2003, p. 280.

Recebido em 03/03/2009

Aceito em 15/07/2009 